San Jose State University

From the SelectedWorks of David W. Parent

October, 2018

\title{
Examination the impact of various factors on student success in an introduction to circuit analysis course
}

David W Parent, San Jose State University 


\title{
Examination the impact of various factors on student success in an introduction to circuit analysis course
}

\author{
David W. Parent \\ Electrical Engineering \\ San Jóse State University \\ San Jóse, CA 95192 \\ David.Parent@sjsu.edu
}

\begin{abstract}
In this work in progress, several models to predict student success in a sophomore introduction to circuit analysis class were created based on prior grade point average, grade in a pre-requisite physics class, the semester the pre-requisite physics class was taken, the number of units a student was taking, the number of times a student repeated the circuits class, and the number of times a student repeated any class prior to enrollment. While all models were statistically significant, the model that included prior GPA and the grade in a pre-requisite physics was the most significant for the data collection effort. While further study is needed, this is an important first step in creating a reliable model of student success that can be used to investigate educational treatments.
\end{abstract}

Keywords-Prior GPA, entry behaviors, circuits, student success, DFW, directed self-placement

\section{INTRODUCTION}

Given that introduction to circuit analysis courses are a part of most engineering programs and usually are on the critical path to graduation, student success in these courses has been the subject of much research. Computer/Web based environments $[1,2]$, blending of lecture and project based learning [3], improved presentation materials [4, 5], flipped classroom [6], and textbook selection [7] have been studied in the past. Recently the author was able to improve the DFW rate (The percentage of students who earn D, F or W.) in our offering of this course by implementing a unique stay/add/drop policy [8]. As part of this policy, students were allowed to take the introduction to circuits class even if they only earned a $\mathrm{C}$ - in the physics pre-requisite class. (A $\mathrm{C}$ or better is required.) Based on the success of the stay/add/drop policy, the author wanted to find out how important the prerequisite grade was in determining student success, along with other factors such as when the students took the prerequisite class, or how many units the student were taking during the semester they took the introduction to circuits class. The extra costs to students who have to retake a course is significant due to student loans, living expenses, and lost wages due to delayed graduation.
The DFW rate since the adoption of the stay/add/drop policy rate for our introduction circuit analysis course vs. class size can be seen in figure 1, where it appears that class size is another factor in student success. Before the case can be made for class size reduction, a model of student success based on incoming student behaviors (such as prior grade point average, and pre-requisite grades) must be created to normalize each class section.

Prior GPA is used frequently to take into account any differences in student groups due to the fact that in most educational environments random student assignment to a treatment section cannot be done. Researchers have used prior GPA in conjunction with pre-requisite grades [9-11], prior GPA and attendance [12-16], and prior GPA as a proxy for student motivation [17-19] to model/study student success. Prior GPA has also been used to study retention [20, 21].

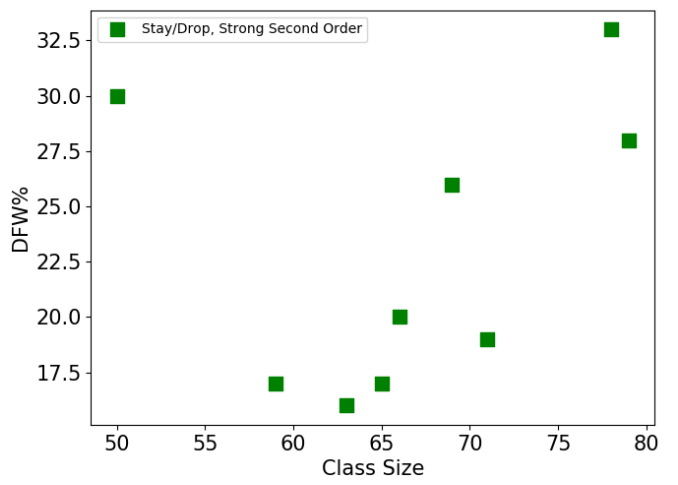

Figure 1: DFW\% vs. Class size after treatment after stay/add/drop treatment was implemented.

While prior GPA (PGPA) and grades in the pre-requisite courses have been used to predict student success in classes, other factors were included in this work based on teaching and advising experience. Factors such as when the student took the pre-requisite physics class (PHYSEM) was included because it was proposed that students would forget what they learned if too much time passed between taking a course and 
its pre-requisite. The number of units the student was taking (NUNIT) during the current semester (CSEM) was included because many advisors feel that students would not pass the circuits course because they took too many units to keep up with the work. The number of times a student attempted the circuits course (NATMP) or number of times a student had to repeat any course (NREP) were included to account for the fact that due to grade forgiveness, the student data on repeats or attempts is deleted.

\section{Methodology:}

Students were allowed to choose which section of introduction to circuit analysis to enroll in, but had to earn $90 \%$ average on their homework (automatically graded through MyOpenMath) for approximately three weeks in order to stay enrolled [8]. The physics pre-requisite and differential equations co-requisite were checked by the faculty after the semester began. Even though the prerequisite for the physics course was a $\mathrm{C}$ or better, those students with only a C- were allowed to stay. All other students who did not meet the pre-requisite were dis-enrolled.

Three multifactor regressions (studies one to three) were carried out for section $1(n=59)$, and two multifactor regressions (studies four and five) were conducted for section $2(n=66)$. The details of each study's factor can be seen in table 1 and the results can be seen in table 2 . While the instructors were different, both used the same course materials [8]. Study one consisted of a six factor regression with PGPA, PHYGPA, PHYSEM, NUNIT, NATMP, and NREP as factors. Study two consisted of a three factor analysis with of PGPA, PHYGPA, and PHYSEM as factors. The final study with sections one's data was a two element regression with just PGPA and PHYGPA as factors. Studies two and three were repeated for section two's data, which resulted in studies four and five. The data was gathered by "hand" looking at each student's transcript and student records were spot checked for accuracy. The variables and terms are summarized in table 1.

Table 1: Variable/Terms Definitions

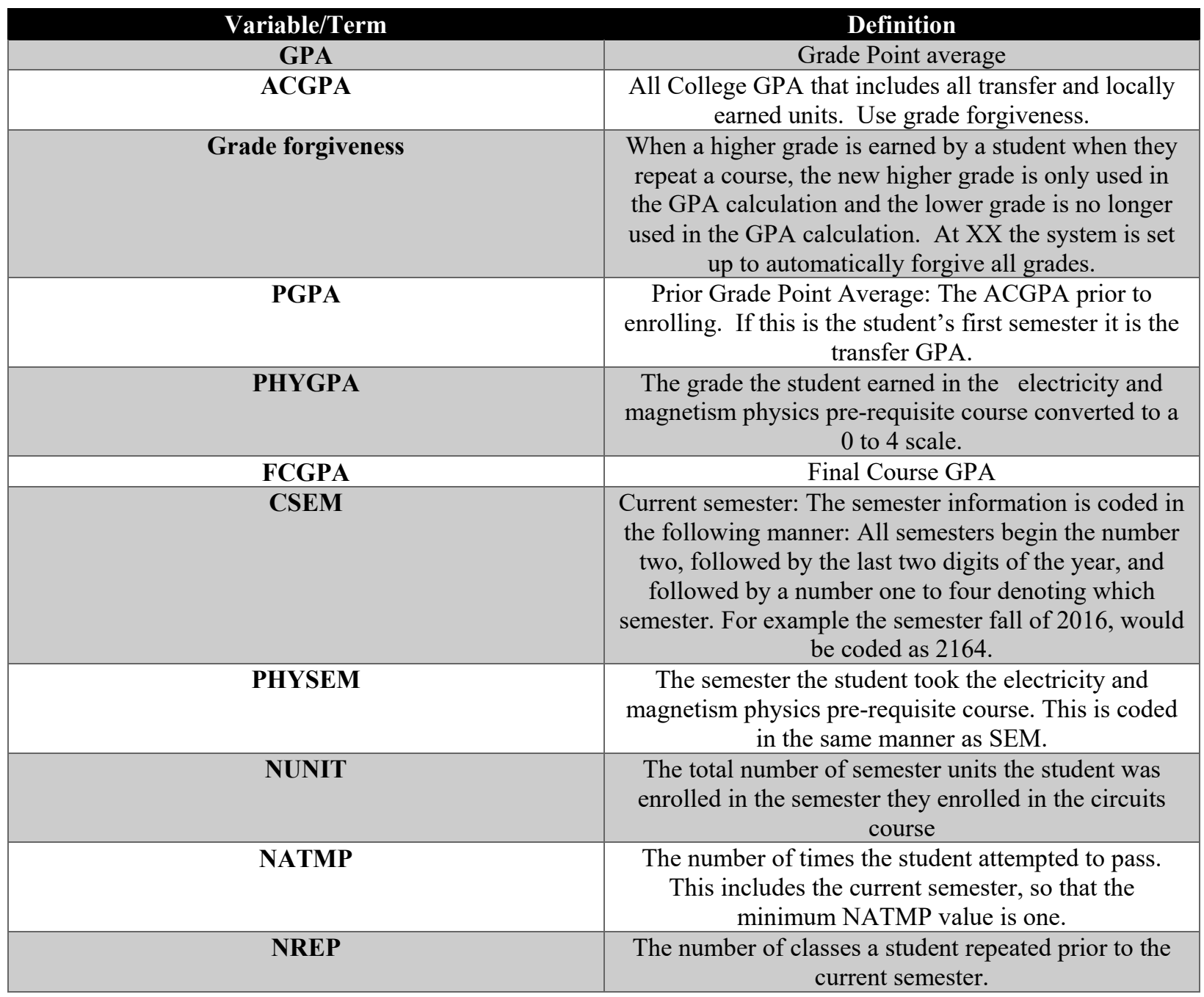




\section{RESULTS AND DISCUSSION:}

The coefficients, intercepts and significance are summarized in table two. All of the studies are statistically significant given that they have significance values less than 0.05 . The coefficients for PGPA appear to be larger than PHYGPA indicating that PRGPA predicts student performance better than the grade in the pre-requite physics class. Interestingly, the number of units (NUNIT) a student was taken has a positive coefficient, which indicates that the more "full time" a student is, they better they do in the course. The number of attempts (NATMP) to pass the circuits' course has a positive coefficient indicating that student who are repeating most likely will pass. In the future, this factor should not be included because we are interested is developing a system in which students pass the first time. The number of courses a student has repeated in the past has a negative coefficient, which is expected as high performing student tend not to repeat classes. (This information should be included in GPA, but with grade forgiveness, this information is lost.) The coefficients for studies two and four seem to have conflicting coefficients for PHYSEM, which indicates this might not be as reliable as other factors. The simplest model of student success just includes PGPA and PHYGPA. Even though only two factors are used (studies three and five), both models are statistically significant, and require the least amount of effort to collect the data.

While $\mathrm{R}^{2}$ values in the physical sciences need to be greater than .60 , in the field of social science $\mathrm{R}^{2}$ values of greater than .10 (studies 3-5) are considered acceptable [22, 23]. The reason that these lower values are acceptable is due to the fact that in social sciences there are no perfect instruments to measure knowledge or motivation, there are just proxies for them. For instance, GPA is used as a proxy for motivation, but it can be contaminated by other factors in a student's life such as homelessness, food insecurity, or family issues. Even the grade in a course is only proxy for what the student has learned.

Even though studies one (six factors) and two (three factors) had higher $\mathrm{R}^{2}$ values $(0.25$, and 0.201 respectively) than the studies three and five which only used two factors, a six factor analysis was not completed on section two due to the fact that the $\mathrm{R}^{2}$ values of 0.1 are acceptable, the significance values of the simpler models were statically significant, and the cost of collecting the six factor data was prohibitive.

To visually interpret the two factor model, the two factor model for section two was plotted vs. the student's final GPA (FGPA) in the course in figure 2 . The model is given by the equation (data extracted from table 2, study 5):

$F G P A=0.93533 \times P G P A+0.15658 \times P H Y G P A-.8006$

The model is plotted against the model (blue dots) so that the prediction can be model can be compared to the student's final GPA (orange dots). Out of five students who were predicted to earn a GPA of less than 2.0, three did not pass, while two students did much better than expected. Approximately 10 students who were predicted to pass, did not, while approximately 10 students were expected to just pass did much better than expected. This warrants further qualitative research to find out why some students were resilient [24] to the threats of low prior GPA and prerequisite grade so that their success can be repeated.

Of course finding out why some students did much worse than expected should be studied for items such as family financial stability, food/housing security or military commitments so that university resources or advising can be better allocator or improved.

Table 2: Results of five studies.

\begin{tabular}{|c|c|c|c|c|c|c|c|c|c|}
\hline Study & Intercept & PGPA & \multicolumn{1}{c|}{ PHYGPA } & \multicolumn{1}{c|}{ PHYSEM } & NUNIT & NATMP & \multicolumn{2}{c|}{ NREP } & Significance \\
\hline 1 & -34.552 & 0.53076 & 0.11745 & 0.01587 & 0.02325 & 0.69707 & -0.05222 & 0.01674 & 0.250 \\
\hline 2 & -34.901 & 0.73546 & 0.04121 & 0.01631 & NA & NA & NA & 0.00591 & 0.201 \\
\hline 3 & -0.27744 & 0.90683 & 0.07763 & NA & NA & NA & NA & 0.04315 & 0.106 \\
\hline 4 & 12.153 & 0.94983 & 0.16819 & -0.00602 & NA & NA & NA & 0.00700 & 0.176 \\
\hline 5 & -0.8006 & 0.93533 & 0.15658 & NA & NA & NA & NA & 0.00241 & 0.174 \\
\hline
\end{tabular}




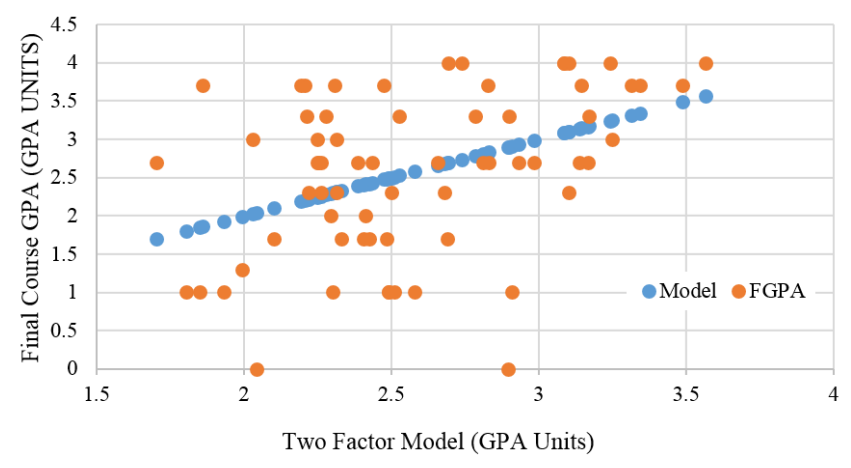

Figure 2: Scatter plot of two factor model vs. final course GPA (FCGPA).

\section{CONCLUSIONS:}

While all the models generated for both sections are statistically significant, a further study needs be conducted based on the average prior GPA and average grade in the prerequisite course with the course section as the unit of study so that treatments can be for reliably studied. For example, there have been nine sections where the stay/add drop/policy has been implemented (Fig. 1). It seems likely based on fig 1, that class size could be a factor in student success. Even though there have been studies that link class size to attendance and thus student success [12-16], there is resistance to this idea on the part of administrators, and faculty. A model based on the average of each sections PGPA and PYSGPA could be used as part of three factor model that could be used to determine class size that could make a strong case for class size reduction from 80 to 60 students per section.

Additional study is also needed because these models only predict the group's performance and not the individual's performance, a study of why those students who did well in the class even though the model predicted that they would not do well, needs to be conducted so that we can improve student advising, or maybe develop supplemental instruction so all students can succeed.

The name of the stay/add/drop policy [8] should be changed to directed self-placement because in practice the number of students who are un-enrolled against their wishes is close to one per 240 students per semester. Most of the drops are done by the student or at the request of the student. For the fall of 2017, 42 students dropped the course themselves and eight students were dropped by the instructor at the student's request. Change the name from stay/add/drop policy to directed self-placement would also make the students feel more welcome.

\section{REFERENCES}

[1] J. Reisslein, R.K. Atkinson, P. Seeling and M. Reisslein, "Encountering the expertise reversal effect with a computer-based environment on electrical circuit analysis," Learning and instruction, vol. 16, no. 2, pp. 92-103 2006.
[2] L. Weyten, P. Rombouts and J. De Maeyer, "Web-based trainer for electrical circuit analysis," Education, IEEE Transactions on, vol. 52, no. 1, pp. 185-189 2009.

[3] N. Hoic-Bozic, V. Mornar and I. Boticki, "A blended learning approach to course design and implementation," Education, IEEE Transactions on, vol. 52, no. 1, pp. 19-30 2009.

[4] A.M. Johnson, K.R. Butcher, G. Ozogul and M. Reisslein, "Introductory circuit analysis learning from abstract and contextualized circuit representations: Effects of diagram labels," Education, IEEE Transactions on, vol. 57, no. 3, pp. 160-168 2014.

[5] J. Reisslein, A.M. Johnson and M. Reisslein, "Color coding of circuit quantities in introductory circuit analysis instruction," 2014.

[6] G.J. Kim, E.E. Patrick, R. Srivastava and M.E. Law, "Perspective on flipping circuits I," Education, IEEE Transactions on, vol. 57, no. 3, pp. 188-192 2014.

[7] D. Sangam and B.K. Jesiek, "Conceptual gaps in circuits textbooks: A comparative study," IEEE Transactions on Education, vol. 58, no. 3, pp. 194-202 2015.

[8] D.W. Parent, "Novel gateway stay/add policy used to increase student success rates in an introductory circuits class," in Frontiers in Education Conference (FIE), 2017, pp. 1-8.

[9] D. Abdulrahman Yousef, "Success in an introductory operations research course: A case study at the united arab emirates university," International Journal of Educational Management, vol. 23, no. 5, pp. 421-430 2009 .

[10] J. Reisslein, M. Reisslein and P. Seeling, "WIP: Effectiveness of worked examples and fading in introductory electrical circuit analysis for learners of different ability levels," in Frontiers in Education, 2005. FIE'05. Proceedings 35th Annual Conference, 2005, pp. S2H-S2H.

[11] B.C. Phillips, S. Spurling and W.A. Armstrong, "Associate degree nursing: Model prerequisites validation study. california community college associate degree programs by the center for student success, A health care initiative sponsored project." 2002.

[12] D.J. Lamdin, "Evidence of student attendance as an independent variable in education production functions," The Journal of educational research, vol. 89, no. 3, pp. 155-162 1996.

[13] S. Devadoss and J. Foltz, "Evaluation of factors influencing student class attendance and performance," Am.J.Agric.Econ., vol. 78, no. 3, pp. 499-507 1996.

[14] G.C. Durden and L.V. Ellis, "The effects of attendance on student learning in principles of economics," Am.Econ.Rev., vol. 85, no. 2, pp. 343-346 1995 .

[15] D. Romer, "Do students go to class? should they?" Journal of Economic Perspectives, vol. 7, no. 3, pp. 167-174 1993.

[16] N. Fang and J. Lu, "Work in progress-a decision tree approach to predicting student performance in a high-enrollment, high-impact, and core engineering course," in Frontiers in Education Conference, 2009. FIE'09. 39th IEEE, 2009, pp. 1-3.

[17] V. Fayowski and P. MacMillan, "An evaluation of the supplemental instruction programme in a first year calculus course," International Journal of Mathematical Education in Science and Technology, vol. 39 , no. 7, pp. 843-855 2008.

[18] E. Szu, K. Nandagopal, R.J. Shavelson, E.J. Lopez, J.H. Penn, M. Scharberg and G.W. Hill, "Understanding academic performance in organic chemistry," J.Chem.Educ., vol. 88, no. 9, pp. 1238-1242 2011.

[19] D.H. Schunk and B.J. Zimmerman, "Work habits and self-regulated learning: Helping students to find a "will" from a "way"," in Motivation and self-regulated learning, Anonymous : Routledge, 2012, pp. 209234.

[20] J.R. Hollenbeck, C.R. Williams and H.J. Klein, "An empirical examination of the antecedents of commitment to difficult goals." J.Appl.Psychol., vol. 74, no. 1, pp. 181989.

[21] D. A. Trytten, and A. McGovern, "Moving from managing enrollment to predicting student success." in Frontiers in Education Conference, 2017. FIE'17. 47th IEEE, 2017, pp. 1-9.

[22] J. Cohen, "A power primer." Psychol.Bull., vol. 112, no. 1, pp. 155 1992. 
[23] J. Cohen, "Statistical power analysis for the behavioral sciences. 2nd," 1988.

[24] J.H. McMillan and D.F. Reed, "At-risk students and resiliency: Factors contributing to academic success," The Clearing House, vol. 67, no. 3, pp. 137-140 1994. 